\title{
The Process by Which Girls Who Develop Type 1 Diabetes before School Age Acquire Self-Management Skills during Puberty and Adolescence
}

\author{
Ayumi Yamasaki1, Yuko Tomari', Ryuzo Takaya², Manabu Ishiro² \\ ${ }^{1}$ Osaka Medical College Graduate School, Osaka, Japan \\ ${ }^{2}$ Osaka Medical College, Osaka, Japan \\ Email: ayu.e.yamasaki@gmail.com, tomari@osaka-med.ac.jp,ped013@osaka-med.ac.jp, ped111@osaka-med.ac.jp
}

How to cite this paper: Yamasaki, A., Tomari, Y., Takaya, R. and Ishiro, M. (2016) The Process by Which Girls Who Develop Type 1 Diabetes before School Age Acquire Self-Management Skills during Puberty and Adolescence. Health, 8, 1788-1806. http://dx.doi.org/10.4236/health.2016.815172

Received: November 12, 2016 Accepted: December 11, 2016 Published: December 14, 2016

Copyright $\odot 2016$ by authors and Scientific Research Publishing Inc. This work is licensed under the Creative Commons Attribution International License (CC BY 4.0).

http://creativecommons.org/licenses/by/4.0/ (c) (i) Open Access

\begin{abstract}
Our aim was to clarify the process by which girls who develop type 1 diabetes before school age acquire self-management skills during puberty and adolescence. We conducted semi-structured interviews with such women who had reached adolescence, and analyzed the results using the modified grounded theory approach (M-GTA). We found the process to be composed of eight categories: Girls begin to feel they understand their own bodies; Girls give precedence to fun, and forget about their disease; Girls build a foundation for taking control of their physical health; Girls feel "out of sync" with their physical sensations; Girls gain new awareness of their disease due to discrimination and comparing themselves to others; Girls revisit their lifestyle and diabetes care practices, with an eye to their future; Girls employ the wisdom and knowledge they have gained from experience; Girls are frustrated at diabetes' relent-less presence in their lives. The learning process could be roughly divided into two periods: a period dominated by annoyance, where girls prioritize fun activities and try to forget about their disease, and a period where they leverage their wisdom to revisit their care behaviors and change their lifestyle.
\end{abstract}

\section{Keywords}

Type 1 Diabetes, Girls, Childhood Development, Self-Management, Puberty and Adolescence

\section{Introduction}

Type 1 diabetes has a prevalence of approximately 1.3/10,000 people in the Japanese 
population, with onset peaking around $11-12$ years of age. The disease tends to afflict women more than men, albeit slightly, accounting for just fewer than $60 \%$ of cases [1] [2]. Every year, slightly more than 500 people newly register to Japan's Medical Aid Program for Chronic Pediatric Diseases of Specified Categories [3].

Type 1 diabetes requires patients to manage their disease on a daily basis throughout their lives. This starts in childhood, when parents take care of most of their child's therapeutic behaviors, and continues through schooling age, when the child starts to be able to take over as well as manage their symptoms under parental supervision [4]. In puberty, when responsibilities for therapeutic behaviors have completely transitioned to the child, they become able to make their own decisions about those behaviors, and to take action based on those decisions [5] [6]. Psychological changes are especially great during puberty, a period where children establish their identity [7] [8] and gender identity [9]. This period is also characterized by rapid increases in the secretion of growth and sex hormones involved in the development of secondary sexual characteristics, leading to significant physical changes. Symptoms of type 1 diabetes worsen in approximately $40 \%$ of young people whose HbAlc levels rise to over $9 \%$ in late puberty due to the influence of these hormones, making glycemic control difficult [10]. Deterioration of glycemic control during puberty is reportedly linked with disease management factors, specifically decreased feelings of self-efficacy, which directly affect a child's mental state [11]. Females are especially at risk: research has identified that, once they begin to menstruate, girls may require higher insulin doses than before due to blood sugar fluctuations that accompany their period [12], and that girls of these ages more often underestimate or overdose insulin than boys, presenting an obstacle to self-management [13]. Moreover, the control achieved during this period has been linked to eating disorders from adolescence onwards [14] [15]. Adolescence presents girls with deeply personal choices that determine their future, in terms of career, marriage, and pregnancy. This likely means they are forced to confront their disease and their personal situation, making it necessary for their therapeutic behaviors to take these options into account. In addition, adolescence is a period where potential pregnancy enters young women's field of view, and they start to consider their disease management with respect to it. When diabetic women become pregnant, pregnancy-related hormones intensify their insulin resistance, raising the risk of congenital fetal malformations due to elevated blood sugar [16]. One study of unmarried women with type 1 diabetes found that about $63 \%$ considered pregnancy to be difficult [17], suggesting the matter evokes complex feelings. The findings above lead us to conjecture that girls in puberty and adolescence face challenges and difficulties with their disease management that differ from those of boys of the same age, making it necessary for them to adjust their therapeutic behavior to something different from ages before. However, we can find no studies to date that have focused on the re-calibration or re-acquisition of self-management skills in girls during puberty and adolescence, a period characterized by great psychological and physical changes. In this study, we focused on how girls with type 1 diabetes, from puberty to adolescence, acquire self- 
management skills that are tailored to their changing bodies and development, with the aim of clarifying the details of this process.

This study aims to clarify the process by which girls who develop type 1 diabetes before school age acquire self-management skills during puberty and adolescence.

\section{Method}

\subsection{Definition of Terms}

\section{Puberty and Adolescence}

Erik Homburger Eriksin defined adolescence as the period between the ages of 12 and 22. Accordingly, we use the term "puberty and adolescence" to mean between the ages of 12 and 22 years in the present study.

\section{Self-management}

We use the term "self-management" to refer to capacity to autonomously regulate one's behavior. For diabetes patients, associated skills include measuring blood glucose and injecting insulin in daily life, regulating one's food and insulin dose according to one's daily activity levels, and the mental ability to, at times of low blood glucose, decide what supplementary foods to eat to deal with the matter oneself.

\subsection{Selection Criteria for Research Subjects}

Secondary sexual characteristics reach complete maturation and the menstrual cycle becomes regular at around $17-18$ years of age [18]. Accordingly, we selected women currently graduated from high school and aged 18 to 35 who had developed type 1 diabetes before school age as our research subjects.

Subjects fulfilled two conditions: 1) Prior to junior high school, they were able to perform therapeutic behaviors for diabetes on their own, including blood sugar measurements, insulin injections, food intake calculations, and techniques for dealing with hypoglycemia; and 2) They were not taking outpatient medication for a mental disorder. The candidate was extracted from the person who fulfilled conditions at random.

\subsection{Data Collection Method}

We contacted pediatricians and physicians at four institutions in the Chūgoku and Kinki regions of Japan, explaining the study objective, methods, and eligibility criteria and requesting them to refer to us potential candidates for the study. Next, on the day of a candidate's outpatient visit, a researcher or physician would give her documentation describing our study aim's and methods. Candidates were asked to return the enclosed reply card if they wished to participate. At a later date, a researcher explained the study purpose and methodology directly to subjects who returned their card, this time verbally, and enrolled her only if she provided consent. For each subject, a researcher conducted a single semi-structured interview in a private room. With the subject's prior consent, interview contents were recorded using an IC recorder and transcriptions made of the content, which were then converted into data. If questions arose about any interview contents, the subject was consulted via phone or e-mail as necessary to check. 
The data collection period was from January through September 2016.

\subsection{Analytic Method}

Interview data was analyzed using the Modified Grounded Theory Approach of Kinoshita [19] [20]. This research methodology is considered useful for discovering problems in the social sciences and elucidating the processes people use to deal with these problems. It is most notably a means of theory formulation for practical use, and useful not only for the description but also the prediction of human behavior. Moreover, it can be applied in the human services domain. Based on the above, we considered the modified grounded theory approach suitable to adopt as our research methodology.

Our study's analytic focus was on "women who developed type 1 diabetes before schooling age, and have transitioned into adulthood from adolescence". Our analytic themes were "therapeutic behaviors and difficulties in girls' daily lives, including their school life in puberty and adolescence; their ways of and tricks for dealing with these difficulties, as well as the resulting changes; and their own thoughts and feelings at this time".

First, transcriptions were made of interview contents, which contained an abundant of specific examples (called "variations" in this methodology). Researchers read the transcripts in their entirety. Next, contents were considered in the context of the overall research focus, and the contents that pertained to our analysis themes were coded, part by part. Afterward, one analysis worksheet was created for each concept, on which the concept's name, definition, and practical examples (variations) were written. Analysis and data collection were conducted in parallel; continuous comparison allowed us to make improvements to concept names and inter-relationships in our model. Categories were created by grouping similar concepts together. After creating the categories, we created a diagram of our results, and developed a written "storyline" of the model based on it.

To increase the validity of our analysis, we presented our results to the subjects of the study and asked for their opinions.

\subsection{Ethical Considerations}

This study was performed after obtaining the approvals of the Ethics Committee of authors' affiliated institutions and, when necessary, of the Ethics Committees of the medical institutions we requested to introduce candidate participants to us.

As for participants who consented to meet after the referral, the researchers directly explained to them, in writing and verbally, the research objective and methodology, that they would not suffer any medical care-related disadvantage as a result of declining to participate, or of quitting midway, and how their personal information would be handled. Only women who consented after receiving this information were included in the present study. In addition, some minors were among our subjects: in these cases, the interview was carried out after obtaining the consent of both the subject and one of her parents. 


\section{Results}

\subsection{Background of Subjects}

Eighteen participants were interviewed, with an average age of 24.0 years (range: 19 - 34 $y)$, an average age of diabetes onset of 8.1 years (2 - $14 \mathrm{y}$ ), and an average disease duration of 16.3 years ( 6 - 28 y). Each subject was interviewed once, for an average of 64.8 minutes (42 - $101 \mathrm{~min})$.

To increase the sample size based on theoretical sampling [21] considerations, two women who developed diabetes before junior high school were interviewed, although our initial aim to was examine only women who did so before then. A total of 18 subjects were thus interviewed and their responses analyzed. Of the 18 interviewees, six developed diabetes as infants or toddlers (age $\leq 6$ ), five did so in early school age (age 7 - 9), five did so in late school age (age 10 - 12), and two did so as junior high school students (age $\geq 13$ ). Eight women got their first menstrual period in late school age, while nine did so in junior high school (this information was unclear for one woman). Twelve of the women had past experience participating in a diabetes camp.

In terms of current education and employment status, seven of the women were students at vocational schools and universities, eight were employed, and three were housewives or otherwise classified. Only five women were using continuous subcutaneous insulin injection (CSII) as a therapeutic management method.

\subsection{Storyline (Figure 1)}

Girls who develop type 1 diabetes before school age take over their therapeutic behaviors, once their parents' responsibility, as they enter puberty. During this time, girls enter a state of mind where they begin to feel they understand their own bodies, as they learn and get used to the essential range of therapeutic behaviors, and make judgments by themselves, about which they feel some uncertainty. From about junior high school, students' lives begin to center around fun and they try to forget about their disease: they give precedence to fun activities as they interact more frequently with friends and snack heavily, and they rebel against the interference of their concerned parents in their therapeutic behaviors. Girls start to report feelings of sensory information being "out of sync" with their physical condition through junior high school and as they enter high school: these experiences are connected to their measuring blood glucose less frequently as they get older, and overlap with their performing therapeutic behaviors less responsibly as they lead independent lives: e.g. getting involved in more activities as they advance to higher levels of education or become employed.

Parallel to these trends, girls start to build a foundation for taking control of their physical health. These efforts include exploring ways to regulate their blood sugar adapted to their individual lives - specifically, making repeated adjustments to injection doses and food intake in response to increased activity levels accompanying club activities and extended class time-and struggles with and searching for solutions to regulating their blood sugar during their first menstrual period, with its accompanying hyperglycemia and related symptoms. 


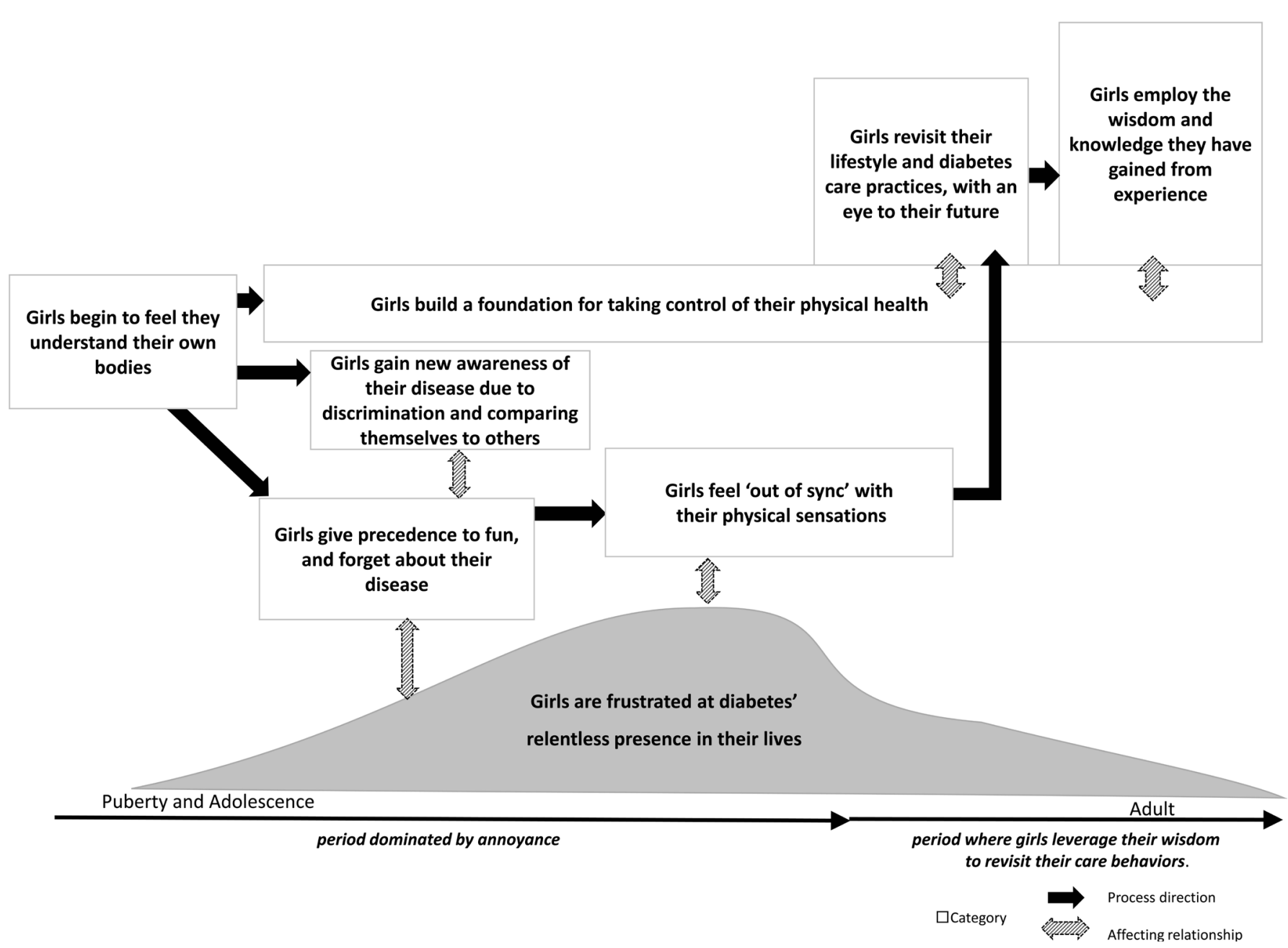

Figure 1. The process by which girls who develop type 1 diabetes before school age acquire self-management skills during puberty and adolescence.

Once they enter puberty, girls become aware of differences between their lives and those of their siblings and friends, such as their self-injections, blood glucose measurements, and restricted eating habits, which they had regarded as unremarkable immediately after developing diabetes. At the same time, girls gain new awareness of their disease due to discrimination and comparing themselves to others, through experiences of invisible discrimination at their part-time jobs. This awareness additionally leads girls to avert their attention from their disease, and to place greater value on fun activities and forgetting about the disease.

Girls feel a new sense of responsibility for their therapeutic behaviors as a result of living alone or employment at the critical junction spanning the period from immediately before graduating high school through advancing to e.g. university or finding employment. This period serves as a turning point where girls can revisit their lifestyle and diabetes care practices with an eye to the future. These changes are prompted by interactions with the opposite sex and ensuing thoughts of potential motherhood, as well as by revisiting their lifestyles after becoming newly cognizant of the fear of their 
situation worsening or complications. the latter may be because of acquaintances with diabetes who develop medical complications, or because of personally failing to adequately control their blood sugar. Girls later make the decision to disclose their diabetes status selectively, to protect themselves, after experiencing invisible discrimination. In addition, girls perform their therapeutic behaviors while employing the wisdom and knowledge they have gained from experience, improvements that derive from their searching for information and utilizing care-related skills. At the same time, girls resume regular blood glucose measurements that they had neglected, becoming able to associate blood glucose measurement values with their own physical sensations, and enjoying heighted physical sensations as a result. Thanks to the foundation for taking control of their physical health girls had been building since entering junior high school, they assign new meaning to their current living habits, as well as to fluctuations in and worsening of blood glucose values.

Underlying this whole process starting in puberty is continuous frustration at diabetes' relentless presence in their lives, with regard to its accompanying injections, blood glucose measurements, dietary restrictions, needing to explain their disease to people unfamiliar with it, and performing the injections in secret. This frustration also affects girls' tendency to try and forget about the disease, and focus on fun activities instead. Moreover, this irritation gradually amplifies, and greatly associates with girls feeling their sensory information is "out of sync". Girls' irritation does diminish as they continue the process of employing the knowledge they have gained from experience, but it never completely disappears. Our results reveal that the above-mentioned process from puberty to adolescence can be roughly divided into two periods: a period dominated by annoyance, and a period where girls leverage their wisdom to revisit their care behaviors.

\subsection{Description of Extracted Concepts and Categories (Table 1)}

We can construct the process by which girls who developed type 1 diabetes before school age acquire self-management skills during puberty and adolescence using the categories below. For each category, we describe its meaning, its constituent concepts, and representative 'variations' for each concept (i.e. excerpts from raw data).

Categories are indicated with bold font, concepts with italic font, and variations with quotation marks.

\section{1) Girls begin to feel they understand their own bodies}

This category covers girls' familiarity and confidence with therapeutic behaviors, conferred by their ability to perform most therapeutic behaviors on their own before entering puberty. It also covers concerns girls feel about judgments they make based on beliefs of self-efficacy, as well as misguided concerns towards the people around them.

This category consists of three concepts: Girls learn and get used to the essential range of therapeutic behaviors, Girls feel uncertainty surrounding their own judgments, and Girls give greater concern to those around them than to themselves.

Girls learn and get used to the essential range of therapeutic behaviors 
Table 1. Overview of categories and concepts.

\begin{tabular}{|c|c|}
\hline Category & Concept \\
\hline $\begin{array}{l}\text { Girls employ the wisdom and knowledge they } \\
\text { have gained from experience }\end{array}$ & $\begin{array}{l}\text { Girls search for information and utilize care-related skills } \\
\text { Girls associate blood glucose measurement values with their own physical sensations } \\
\text { Girls experience heightened physical sensations } \\
\text { Girls disclose their diabetes status selectively, to protect themselves }\end{array}$ \\
\hline $\begin{array}{l}\text { Girls revisit their lifestyle and diabetes care } \\
\text { practices, with an eye to their future }\end{array}$ & $\begin{array}{l}\text { Girls revisit their lifestyle after becoming newly cognizant of the fear of their situation } \\
\text { worsening or complications } \\
\text { Girls start to think about potential motherhood } \\
\text { Girls feel a new sense of responsibility for their therapeutic behaviors as a result of living alone } \\
\text { or employment }\end{array}$ \\
\hline $\begin{array}{l}\text { Girls are frustrated at diabetes' relentless } \\
\text { presence in their lives }\end{array}$ & $\begin{array}{l}\text { Girls feel annoyed to have to suspend their daily activities to perform injections and blood } \\
\text { glucose measurements } \\
\text { Girls feel explaining the disease to people is bothersome } \\
\text { Girls feel annoyed about hiding their injections } \\
\text { Girls feel relocating to the school infirmary to perform injections is bothersome }\end{array}$ \\
\hline $\begin{array}{l}\text { Girls feel "out of sync" with their physical } \\
\text { sensations }\end{array}$ & $\begin{array}{l}\text { Girls measure blood glucose less frequently as they get older, leading them to become } \\
\text { disconnected from their physical sensations } \\
\text { Girls perform therapeutic behaviors less responsibly as they lead independent lives }\end{array}$ \\
\hline $\begin{array}{l}\text { Girls give precedence to fun, and forget about } \\
\text { their disease }\end{array}$ & $\begin{array}{l}\text { Girls rebel against parental interference in therapeutic behaviors } \\
\text { Girls prioritize fun activities, and forget about their disease } \\
\text { Girls become concerned about changes in their figure due to insulin regulation }\end{array}$ \\
\hline $\begin{array}{l}\text { Girls gain new awareness of their disease due to } \\
\text { discrimination and comparing themselves to } \\
\text { others }\end{array}$ & $\begin{array}{l}\text { Girls experience invisible discrimination } \\
\text { Girls become aware of differences between their lives and those of their siblings and friends }\end{array}$ \\
\hline
\end{tabular}

"My parents would nag me: they would say like, 'Did you inject yourself?', 'Did you eat?', 'Did you measure your blood sugar?', and I would reply like, 'Yeah, yeah'. Once I got a bit more used to them, I would initiate the injections myself, thinking like, 'I guess that's all?"' ID13

Girls feel uncertainty surrounding their own judgments

"In junior high school, my blood sugar was like a storm, swinging from high to low. I think maybe the reason my blood sugar got so low was because I injected quite a lot [of insulin] when it was high. I was fine injecting 16 to 20 [IU per dose] on a regular basis. I did know that one unit dropped [blood glucose] levels by about $50[\mathrm{mg} / \mathrm{dL}]$, I was told as much in elementary school.

Even so, I'd think [blood glucose] would decrease immediately, [it would] drop if I injected a lot." ID4

Girls give greater concern to those around them than to themselves 
"The classroom was far from the school infirmary. We would all eat our packed lunch together, and I really hated coming back from it late and making my friends wait. The bathroom was close to the class, so I would manage my blood sugar [i.e., injections and blood glucose measurements] quickly in the bathroom, like, it was fine if I just took care of it, bam-bam. So I kind of neglected it." ID12

2) Girls give precedence to fun, and try to forget about their disease

This category covers girls giving precedence to interactions with friends in their school lives as well as the fun things in life, as they put the reality of their type 1 diabetes in the back of their minds. It also regards their neglect of therapeutic behaviors as they rebel against their worried parents.

This category consists of three concepts: Girls rebel against parental interference in therapeutic behaviors, Girls prioritize fun activities, and forget about their disease, and Girls become concerned about changes in their figure due to insulin regulation.

Girls prioritize fun activities, and forget about their disease

"I was quite naughty in junior high school. I'd not [do my insulin injection], they'd say 'Inject yourself', and then I'd finally start moving 30 minutes later. What it was, I would find things I wanted to do more than the injection, like my favorite manga, which I loved. Or I'd want to play with my friends. That and that only." ID11

Girls rebel against parental interference in therapeutic behaviors

"It was my rebellious period. Your parents tell you, you know, 'Measure [your blood sugar]'. I'd get annoyed, and complain, like, 'Just leave me alone'. So I gradually started to hate measuring it, it was so, so annoying." ID9

Girls become concerned about changes in their figure due to insulin regulation

"When you're a junior high school student in puberty, when you eat and drink so much, you could care less about the disease. My hormones also started to change, which made me put on weight more easily, and so I got fat. My mom told me, 'You shouldn't inject yourself with lots of insulin to lower [your blood sugar], because it makes you hungry, then you'll eat and get fat'. That, at least, I paid attention to, kind of. I tried to avoid injecting too much [insulin] and getting hypoglycemic, and to not eat unnecessarily." ID11

"I really hated the mark left on my fingertip [by the blood glucose meter]. I didn't want to measure [my blood sugar], because what would I do if my friends asked about it?" ID18

3) Girls gain new awareness of their disease due to discrimination and comparing themselves to others

This category covers how girls with type 1 diabetes compare themselves with their siblings and friends closest to them, and how they experience employment discrimination at their part-time job or workplace. These experiences make the girls freshly aware of their disease and of their related therapeutic behaviors, once regarded as unremarkable.

This category consists of two concepts: Girls become aware of differences between their lives and those of their siblings and friends, and Girls experience invisible dis- 


\section{crimination.}

Girls become aware of differences between their lives and those of their siblings and friends

"I'd go out to eat or have fun with friends... 'You're not having juice?' 'No, just tea'. Everyone knew I had the disease, but they didn't understand it meant [I couldn't have juice], so it was a little difficult for me to handle emotionally. [...] Everyone knew I had the disease. But one girl who I was really friendly with, when I did an injection while we were having a meal, she said, 'You poor thing' to me. And things kind of soured then, because I really hate being pitied." ID1

Girls experience invisible discrimination

"When I worked part-time at a restaurant, in the job interview I went ahead and told them that I would need to give myself a shot [of insulin] before lunchtime, without specifically mentioning diabetes. The next day I got a phone call. They sent me wages for the days I worked, and returned my resume.[...] I worked my hardest, I did the best I could, but after all that, that I was still thought of as someone with a 'disease'...that was a big shock. [...] I told myself, 'Yep, I shouldn't say anything.'” ID15

\section{4) Girls build a foundation for taking control of their physical health}

This category covers girls' experiences dealing with new difficulties in controlling their blood sugar, which they did not have prior to their first menstrual cycle, their repeated adjustments to injection doses and food intake in response to increased activity levels in their new lives after entering junior high school, and their continuous exploration of how to regulate their blood sugar on their own.

This category consists of two concepts: Girls struggle with regulating their blood sugar during their first menstrual period, and search for solutions, and Girls explore ways to regulate their blood sugar adapted to their individual lives.

Girls struggle with regulating their blood sugar during their first menstrual period, and search for solutions

"I thought I should inject a lot [of insulin], because I was on my period. But I'd have no appetite when I did, as you'd expect. Injecting a lot was okay, but I'd feel sick, or my stomach would hurt, which meant I couldn't eat. So I'd get in a vicious cycle and get hypoglycemic. I think, it sure is hard to control [blood glucose levels].I wonder, how can I control them going forward?" ID2

Girls explore ways to regulate their blood sugar adapted to their individual lives

[At morning practice for a club activity] "In the morning, sometimes it was because I didn't have much time for it, but [my blood glucose levels] would drop fast if I injected a little bit [of insulin]. So I would eat two or three bananas, and then go to practice without injecting myself. In the beginning I would go after eating only one, but they still fell. Well, I thought, if I don't inject myself, how much should I eat before going? After trying out different combinations, I figured out that two or three bananas was just right." ID3

5) Girls feel sensory information is "out of sync" with their condition

This category covers girls' complaints of dulled physical sensations and inaccurate 
predictions of blood glucose due to measuring it less frequently and giving less thought to their therapeutic behaviors. These phenomena appear despite girls' experience with estimating their blood glucose values more or less accurately in the past, thanks to many years of care activities and being familiar with how measurement values are reflected by physical symptoms.

This category consists of two concepts: Girls measure blood glucose less frequently as they get older, leading them to become disconnected from their physical sensations, and Girls perform therapeutic behaviors less responsibly as they lead independent lives.

Girls measure blood glucose less frequently as they get older, leading them to become disconnected from their physical sensations

“My parents weren't there anymore [when I was living alone], so I stopped measuring my blood sugar. More and more, my feelings in moments I felt hypoglycemic and moments I was hyperglycemic got out of sync. I'd be at about $90[\mathrm{mg} / \mathrm{dL}]$ and feel hypoglycemic. The reverse too: more and more, I'd be like at 300 but not feel anything. I'd feel this way, but I believed in myself, I thought I understood what they meant. So I would eat without measuring my blood sugar. 100 or 90 is normal, but I'd eat anyway, and then it would rise to 200 or 300 . But this became the new normal, and my values all got worse. But you know, I was convinced I understood [what the sensory information meant]. My senses were out of whack all the time, because I stopped measuring as a matter of habit." ID4

Girls perform therapeutic behaviors less responsibly as they lead independent lives

"My eating habits changed rapidly when I started living alone. I went to more drinking parties. I don't think alcohol raises blood sugar so much, but because of food and fried foods, I got fat when I was a university student. I started part-time work, and I got fatter. My lifestyle at the time, like, I was gulping down two rice balls before work, then I'd eat something after work too because I was hungry. I put on weight so fast." ID4

6) Girls revisit their lifestyle and diabetes care practices, with an eye to their future

This category covers changes in girls' value systems as they relate to medical care. These changes are prompted by their thinking about or trying to anticipate the future, which in turn are prompted by confrontations with crisis situations, including the girls or those around them potentially developing medical complications, or of their physical condition or ability to control their care worsening. These changes may also be prompted by living alone, employment, and romantic relationships, which can cause girls to start to see their responsibilities and envision their future.

This category consists of three concepts: Girls revisit their lifestyle after becoming newly cognizant of the fear of their situation worsening or complications, Girls start to think about potential motherhood, and Girls feel a new sense of responsibility for their therapeutic behaviors as a result of living alone or employment.

Girls revisit their lifestyle after becoming newly cognizant of the fear of their situation worsening or complications

"When I was in college, I'd take my blood sugar monitor with me, and I'd inject my- 
self after measuring my blood sugar at lunchtime. I think, I was keeping in mind [the occasional need to] supplement [insulin] at the time, so I would take extra needles and stuff as spares.

Maybe I was thinking, 'You have to do it right.' My control [activities] got a little irregular, so I thought, you know, 'You have to', I guess.” ID13

Girls feel a new sense of responsibility for their therapeutic behaviors as a result of living alone or employment

"It was after entering university. Starting to live alone made me start to think. If you fall over in your room, nobody will help you, you know? I thought, I have to be careful. I thought, you know too little about yourself. So I learned more about myself." ID11

Girls start to think about potential motherhood

"They say childbirth is hard, you know. I've heard some women lose their eyesight when they do.[...] But I hear quite a bit, if you're really hypoglycemic, it's a real struggle to do it, I hear some women started to go blind and stuff. I have no idea what to make of the articles about it, but I see the ones that say it's between parents and children, that maybe it's genetic, and sometimes I wonder, you know, can I give birth?" ID6

\section{7) Girls employ the wisdom and knowledge they have gained from experience}

This category covers girls employing knowledge about disease management they have gained through camps, professionals, and friends and others with diabetes. It also covers girls employing their accumulated wisdom (including involvement with people around them) gained from experience of better care provision, and ways to regulate their blood sugar learned through trial and error and through their experiences in life to date.

This category consists of four concepts: Girls disclose their diabetes status selectively, to protect themselves, Girls search for information and utilize care-related skills, Girls associate blood glucose measurement values with their own physical sensations, and Girls experience heightened physical sensations

Girls disclose their diabetes status selectively, to protect themselves

"You definitely start to choose people. When you go out in the adult world, you have to think and decide for yourself, like, I wonder if I should tell this person. You definitely shouldn't be telling everyone, but you should also probably tell people who it would be a bad idea not to tell." ID15

Girls search for information and utilize care-related skills

"If you're just purely counting carbs, your blood sugar definitely rises. If you eat food with lots of fat or protein, it goes up later. I've always added all these kinds up to decide the amount [of insulin] to inject.[...] I do season my food. But, bread, rice balls, whatever it is, I add it all up. It works, for sure." ID3

Girls associate blood glucose measurement values with their own physical sensations

"For me, it's the times when I'm strangely motivated that [my blood sugar is] high. When I feel like cleaning my room, or concentrating on studying, I think, 'Wait a second'. I measure myself and it's like 264 [mg/dL]. Oh, that's why. Now, I understand it suddenly, when I get a mysterious sensation that I'm trying to figure out. I say sud- 
denly, but it's the same as always. But there's also this strange dizzy feeling I get, which is somehow different from usual. Recently, I've been measuring myself when I get this way, if I have time, and it's like, 300. Maybe, even if [my blood glucose] is high when I get strangely dizzy like this...maybe when I've dropped from the high levels, that's when I get dizzy. It would be so convenient if I could just determine it by myself!” ID3

Girls experience heightened physical sensations

"I can tell that [my blood sugar is] high when the moisture in my saliva starts to evaporate. [...] Before I turned 20 or so, maybe this wasn't something I could easily tell from my saliva. I had heard stories before, but that was like, elementary school or junior high school. People who said they feel like they can tell, they were about 20 years old. I thought, maybe I'll be able to tell when I get to that age, and now I can tell." ID11

\section{8) Girls are frustrated at diabetes' relentless presence in their lives}

This category covers how girls hide the fact they have diabetes and their injections, even as they need to repeatedly perform therapeutic behaviors in their lives, day after day. It also covers how girls deal with annoyance at situations that accompany those therapeutic behaviors, such as explaining the disease to people unfamiliar with it.

This category consists of four concepts: Girls feel annoyed to have to suspend their daily activities to perform injections and blood glucose measurements, Girls feel explaining the disease to people is bothersome, Girls feel annoyed about hiding their injections, and Girls feel relocating to the school infirmary to perform injections is bothersome.

Girls feel annoyed to have to suspend their daily activities to perform injections and blood glucose measurements

"When I was in high school, I really didn't want to do the injections, and it was annoying to go to the bathroom to do them. You go to the toilet at certain intervals, you know? But they're not regular intervals. I would like, do the injections when I wanted to go to the bathroom. Like, I won't do them regularly, it's fine if I just do it next time I go to the bathroom. Like, I can just do it after I eat." ID2

"Essentially, I stopped measuring my blood sugar from about junior high school, and my management was pretty spotty. Measuring it started to feel really annoying. I didn't even really do it at home. But when I was in elementary school, I'd do it four times a day, like clockwork. In junior high, it was maybe once a day." ID9

Girls feel annoyed about hiding their injections

"When I would eat my packed lunch with friends, it would be annoying if every time I were like, 'Be right back, going to the bathroom to do my injection!' So I just did them in front of everyone." ID17

Girls feel relocating to the school infirmary to perform injections is bothersome

"The school infirmary was on the same floor until the first year of junior high, so I would go without complaint. But it became more of a hassle. It was a hassle to go now because now it was far away. The cafeteria would get crowded, and I didn't want to eat apart from everyone at mealtime, so the infirmary quickly became a thing of the past." ID4 


\section{Girls feel explaining the disease to people is bothersome}

"I didn't tell so many people in high school. It would have been a hassle. There's no need to tell them anyway, I thought. I could just tell them if they were about to find out. Explain if they asked, basically.” ID9

\section{Discussion}

Our results reveal that the process by which girls who develop type 1 diabetes before school age acquire self-management skills for the disease is characterized by two periods during puberty and adolescence: a period dominated by annoyance, and a period where girls leverage their wisdom to revisit their care behaviors. We discuss the topic in light of these periods, from the following four viewpoints.

1) Building a foundation for self-management at school age, cultivated in a protected environment

Most cases of type 1 diabetes develop in children by school age, peaking at $11-12$ years old [1]. Insulin injections, blood glucose monitoring, and other therapeutic behaviors must become ingrained in children as a part of their lives. Once children reach school age, the bulk of each day is spent at school, making this period an important one for the responsibility for most therapeutic behaviors to transition to children. The school itself serves as the location where children acquire the skills for self-managing these behaviors.

Once they have matured to puberty and adolescence, girls begin to feel they understand their own bodies, a feeling that begins in puberty. Upon entering puberty and interacting more frequently with their friends, they try and forget about their disease, and focus on fun activities instead. Our interviewees' feelings of sensory information being "out of sync" with their condition are a result of two kinds of accumulated experiences: measuring blood glucose less frequently as they get older, leading them to become disconnected from their physical sensations, and performing therapeutic behaviors less responsibly as they lead independent lives. Children's lives through school age is an important time: they should be provided with a sheltered environment, protected by parents and school officials, to provide them with fertile ground to take over necessary therapeutic behaviors. We predict that a child will frequently measure their blood glucose if her environment and surroundings allow her to perform therapeutic behaviors; the children will unconsciously connect her blood glucose values with her physical symptoms, developing an intuitive feeling, which they will remember over the course of repeated daily checks. We posit that it is precisely their memory of this sensation from school age, when they did not consider their therapeutic behavior as unusual, that allows them to recognize when they feel are "out of sync" with their physical sensations during puberty. For patients with a chronic disease to self-manage, they must not only adopt a suitable lifestyle and behaviors with respect to their disease, but also be able to recognize changes in their condition [22]. Children with type 1 diabetes should be provided with frequent opportunities to measure their blood glucose before school age, in a sheltered environment, so that they can perceive changes in their condition. Cultivating 
the ability to intuitively and physically perceive their physical condition would lead them to connect such sensations with physiological irregularities from puberty onwards.

Kuniyoshi et al. investigated children's therapeutic behaviors in the context of their lives at school. All elementary and junior high school who participated in the study reported feeling supported and understood by their homeroom teachers and school nurses. Moreover, all elementary students performed their insulin injections in the school infirmary, and received high scores for therapeutic behaviors related to selfmonitoring of blood glucose. Their results also indicated that elementary students earned higher performance scores for therapeutic behaviors of meals, insulin injections, and blood glucose measurements than did junior high school and high school students [23]. In summary, children become able to practice therapeutic behaviors properly in an environment where they are protected by those around them. We posit that these behaviors are connected with girls feeling 'out of sync' with their physical sensations, sensory information that underpins their ability to perceive their condition, and thus serves as a foundation for their self-management.

\section{2) Strong frustration at diabetes' relentless presence in their lives}

Our results reveal that the above-mentioned process from puberty to adolescence can be roughly divided into two periods: a period dominated by annoyance, and a period where girls leverage their wisdom to revisit their care behaviors. In this process, beginning in puberty, girls carry with them feelings of frustration at diabetes' relentless presence in their lives. These feelings regard the insulin injections, blood glucose measurements, and dietary adjustments girls have needed in their lives since before junior high school, as well as explaining their disease to people around them who are unfamiliar with it and performing injections in secret.

Our results support those of previous studies, which have found that, during puberty, students regard meals and therapeutic behaviors like injections and blood glucose measurements as bothersome: the reasons they found included poor timing and lack of suitable location [24] [25].

Inaoka considers "self-belief, that you can do something by yourself" to be a necessary condition for successful self-care [26]. While our interviewees understood the necessity of these behaviors, these annoyances led them to experiment with controlling their blood sugar through trial and error. Through their repeated efforts, the girls laid the foundation for taking control of their physical health. Thereafter, girls employed the wisdom and knowledge they gained from experience in their therapeutic behaviors. Their ability to perform these behaviors was thanks to this "self-belief" as defined by Inaoka: belief in the ability to do something by themselves. The accumulated confidence the girls acquired by repeated efforts to build a foundation for taking control of their physical health provides them with one kind of opportunity to overcome the irritations. We posit that these efforts also constitute one step of the process by which girls acquire self-management skills.

3) Nursing care's importance in ascertaining the transition to the period where 


\section{girls leverage their accumulated wisdom to revisit their care behaviors}

Our results revealed that girls transition to the period where they leverage their accumulated wisdom to revisit their care behaviors around age 20, when they move on to university or find employment. For patients with type 1 diabetes or other chronic diseases, this period overlaps with another transition: that from visiting a pediatric specialist to an internist. In their reports, Mochizuki [27] and Kikuchi [28] respectively noted that type 1 diabetes patients prepare for this transition upon turning 15 in the USA, and demonstrated the importance of assessing the independence and mental condition of an adolescent before moving forward with it. How patients with chronic diseases transition to adulthood has become a topic of discussion in Japan as well, with many continuing to visit their pediatric specialists even after reaching adult age. It is important that medical professionals fully understand the information we present, in order to ascertain the transition period to the period where girls leverage their accumulated wisdom to revisit their care behaviors observed in our results. We believe this transition cannot be simply systematized: nurses must reflect together with their patients, encouraging them to realize and not miss this period when transition is possible. In this vein, our results also suggest the necessity of investigating this transition period, tailoring care to individual patients' situations, and of making a system with the input of professionals in pediatrics and internal medicine. This will ensure that patients are not transferred to an internist without first establishing important information and relationships.

Considering puberty and adolescence to be the period between the ages of 12 and 20, Erikson writes that the development and expansion of children's identities pose developmental challenges. Children identify less with their parents and important third parties as the need emerges for them to acquire an identity: i.e., who they themselves are [7] [8]. Further, a child's recognition of her roles and values is an essential key to helping them overcome these challenges. During this period, living with diabetes means children must redefine the relationship of the self with others. They do so by reconsidering the meaning of their diabetes through their relationships with important people in their lives, and rebuilding the relationships with those important people who support them [29]. One study of Japanese university students found that a person's identity is largely established in the third year of university, around 20 years of age, and that this establishment of identity coincides with students revisiting their care activities. We believe that encouraging patients to pay attention to such concepts will have positive effects on their image of themselves (specifically, as being someone with a disease), and on their future therapeutic behaviors [30].

\section{4) Necessity of gender-based support methods}

Our interviewees reported experiencing heightened physical sensations around age 20: specifically, increased oral cavity sensitivity to blood glucose fluctuations. Some studies have reported on the relationship between hyperglycemia and nerve damage, stating that patients regain normal sensitivity in their bodies and nerves as their blood glucose patterns stabilize after puberty, no longer influenced by the sex and growth 
hormones previously inducing the development of secondary sexual characteristics [31] [32]. Our study was unable to confirm whether the pattern observed here was the same phenomenon. As stated earlier, gender differences affect patients' self-management of diabetes. However, our interviewees were all women, and as such this study was unable to elucidate gender differences in self-monitoring or body-related concerns during puberty and adolescence. Thus, we believe further investigation on this topic is necessary, specifically targeting boys and men.

One final topic of concern: Okuyama et al. found that the life expectancies of male and female Japanese diabetes patients are respectively 9.6 and 13 years shorter than their healthy counterparts [33]. Our data here suggests the need for more-detailed investigation of support methods for use during puberty and adolescence, a period characterized by especially great physical and mental changes, that take into account gender differences.

\section{Conclusions}

Our study reached the following conclusions.

1) The process by which girls who develop type 1 diabetes before school age acquire self-management skills for the disease is characterized by two periods during puberty and adolescence: a period dominated by annoyance, and a period where girls leverage their wisdom to revisit their care behaviors.

2) During the period dominated by annoyance, girls become familiar with therapeutic behaviors for diabetes, and begin to feel they understand their bodies, which drives them to forget about their disease, and focus on fun activities instead. As their therapeutic behaviors become neglected and insufficient during these fun activities, girls experience feeling "out of sync" with their physical sensations.

3) As girls transition to the period where they leverage their wisdom to revisit their care behaviors, they begin to revisit their lifestyle and diabetes care practices, with an eye to their future, prompted by events such as temporary deterioration in their condition, living alone, and employment. This also leads them to employ the wisdom and knowledge they have gained from experience.

4) Girls' efforts to build a foundation for taking control of their physical health starting in early puberty lead them to employ the wisdom and knowledge they gain from experience, including that of experimenting with controlling blood sugar through trial and error.

5) Even as girls feel frustrated at diabetes' relentless presence in their lives, in the form of therapeutic behaviors, opportunities to revisit their lifestyle and diabetes care practices, with an eye to their future mean that this irritation gradually abates as they enter the stage of employing the wisdom and knowledge they gain from experience.

6) Our interviewees experienced heightened physical sensations around age 20; it is unclear whether this phenomenon differs by gender. Our data suggested the need for more-detailed investigations of the relationship between sensory perceptions and gender, and of support methods that take into account gender differences. 


\section{Acknowledgements}

We would like to express our deep appreciation to all of the women who agreed to be interviewed for their cooperation. We also greatly thank the physicians at the medical institutions we recruited patients from, who assisted us in the selection of participants and advised us on aspects of the research in the midst of their busy clinical schedules.

We have no conflicts of interest to disclose.

\section{References}

[1] Amemiya, S. (2011) Characteristics of Japanese People with Childhood and Adolescent Diabetes and Future Challenges. The Journal of the Japan Pediatric Society, 115, 13-19. (In Japanese)

[2] The Japan Diabetes Society and The Japanese Society for Pediatric Endocrinology (2011) Pediatric and Adolescent Diabetes Management Handbook. Revised 3rd Edition, Consensus Guidelines, Nankohdoh, Tokyo, 50-65. (In Japanese)

[3] Katoh, T. (2004) Percentages of Registered Pediatric Patients for Specified Chronic Diseases. Intractable Disorder Conquest Research Grant: Research on Improvement of Therapeutic Environment for Patients with Specific Child Chronic Diseases: 2003 Annual Summary Research Report. Principal Investigator, Oikawa, I, 5-9. (In Japanese)

[4] Kanematsu, Y. (1986) Involvement of Parents in the Self-Care of Diabetic Children-Based on a Survey of Mothers. Journal of Japan Academy of Nursing Science, 6, 46-47. (In Japanese)

[5] Tani, H. (1998) A Study of Independence of Diabetic Children in DM Self-Care Behaviors. The Journal of Japan Academy of Diabetes Education and Nursing, 2, 88-96. (In Japanese)

[6] Maeda, H. and Soeda, K. (2013) Transition of Care Behavior from Parents to Children in Case of Children with Type 1 Diabetes as Observed from the Parent-Child Relationship. Journal of Japanese Society of Child Health Nursing, 22, 9-16. (In Japanese)

[7] Erikson, E.H. and Erikson, J.M. (2001) The Life Cycle Completed: Extended Version. Murase, T. and Kondoh, K., Trans., Misuzu Shobo, Tokyo.

[8] Erikson, E.H. (1950) Childhood and Society. Vol. 1 and 2, Nishina, Y., Trans., Misuzu Shobo, Tokyo.

[9] Matsumoto, K. (2006) Sex: The Nursing of Sexuality-Aimed at Realizing QOL. Kenpakusha, Tokyo, 63-64. (In Japanese)

[10] Sugihara, S. (2011) From a Diabetes Perspective. The Journal of Child Health, 70, 41-45. (In Japanese)

[11] Hughes, A.E., Berg, C.A. and Wiebe, J.D. (2012) Emotional Processing and Self-Control in Adolescents with Type 1 Diabetes. Journal of Pediatric Psychology, 37, 925-934. https://doi.org/10.1093/jpepsy/jss062

[12] Ohsawa, M. and Uchikata, Y. (2008) How Type 1 Diabetes Patients Should Deal with Poor Blood Glucose Control during Puberty. Practice, 25, 659-665. (In Japanese)

[13] Schober, E., Wagner, G. and Berger, G. (2011) Prevalence of Intentional under-and Overdosing of Insulin in Children and Adolescents with Type 1 Diabetes. Pediatric Diabetes, 12, 627-631. https://doi.org/10.1111/j.1399-5448.2011.00759.x

[14] Urakami, T., Fujii, S., Kubo, M. and Owada, M. (2000) Eating Disorders in Patients with Juvenile-Onset Type 1 Diabetes Mellitus. Clinical Pediatric Endocrinology, 9, 69-74.

[15] Tsukahara, S., Uchikata, Y., Ishidoh, K., Ishida, K., Takii, M. and Iwamoto, Y. (2009) Pre- 
valence and Psychological Aspects of Eating Disorder and Abnormal Eating Habits in Type 1 Diabetes Patients. Journal of the Japan Diabetic Society, 52, 13-21. (In Japanese)

[16] Kahn, C.R., King, G.L., Moses, A.C., et al. (2005) Joslin's Diabetes Mellitus. Kanazawa, T., Kasuga, M., Kashiwagi, A., et al., Trans., 2nd Edition, Medical Science International, Tokyo, 1151.

[17] Tanaka, K., Nakajima, K., Hori, D., Hayashi, H. and Wasaki, Y. (2006) Problem Structuring on the Reproductive Health Women with Type 1 Diabetes Awareness, Knowledge and Support Factors of Reproductive Health. Diabetes and Pregnancy, 6, 119-126. (In Japanese)

[18] Mori, M. (2014) Systematic Nursing Science Course, Field of Study II, Maternity Nursing 1. 12th Edition, Chapter 3, Igaku-Shoin, Tokyo, 177. (In Japanese)

[19] Kinoshita, Y. (2006) Grounded Theory Approach: Rebirth of Qualitative Empirical Research. Kobundoh, Tokyo. (In Japanese)

[20] Kinoshita, Y. (2005) Grounded Theory Approach in Practice. Kobundoh, Tokyo. (In Japanese)

[21] Juliet, C. and Anselm, S. (2012) Basics of Qualitative Research Techniques and Procedures for Developing Grounded Theory. Missao, H. and Morioka, T., Trans., 3rd Edition, Igakusyoin, Tokyo.

[22] Murakami, Y. (2002) Self-Care Education for Children with Chronic Illnesses-A Behavioral Science Approach. Journal of Japanese Society of Pediatric Peritoneal Dialysis, 15, 38-47. (In Japanese)

[23] Kuniyoshi, M., Gushiken, M., Miyagi, K. and Gajya, S. (2003) Self-Care Behavior of Diabetic Children and Its Practice in School Life. The Journal of Japan Academy of Diabetes Education and Nursing, 7, 107-114. (In Japanese)

[24] Komai, Y., et al. (2007) Self-Care Behaviors of Children with Type 1 Diabetes and the Relationship between Children and Their Parents Coping with Dietary Management, Hypoglycemia and Hyperglycemia. Nagano College of Nursing Bulletin, 9, 37-44. (In Japanese)

[25] Kawahigashi, Y., Inagaki, M. and Tasaki, K. (2011) Psychological Characteristics of Patients with Youth Onset Type 1 Diabetes for Many Years. The Journal of Japan Academy of Diabetes Education and Nursing, 15, 4-10. (In Japanese)

[26] Inaoka, F. (1989) Ways of Thinking about Self-Care, and the Assessment of Self-Care Skills. The Japanese Nursing Journal, 10, 32-35. (In Japanese)

[27] Mochizuki, E. (2016) Type 1 Diabetes: Issues with the Transition to Adulthood and Responses. Japanese Journal of Pediatrics, 69, 669-674. (In Japanese)

[28] Kikuchi, N. (2012) Care during Puberty and the Transition to an Internist. The Journal of Pediatric Practice, 12, 86-90. (In Japanese)

[29] Sparud-Lundin, C., Ingbritt, O. and Danielson, E. (2009) Redefining Relationships and Identity in Young Adults with Type 1 Diabetes. Journal of Advanced Nursing, 66, 128-138. https://doi.org/10.1111/j.1365-2648.2009.05166.x

[30] Shiraishi, H. and Okamoto, Y. (2006) The Relationship between Identity Development and Family Functioning in Adolescence. Bulletin of the Hiroshima University Graduate School Training and Research Center for Clinical Psychology, 5, 5-66. (In Japanese)

[31] Seino, H. (2013) Effects of Hyperglycemia on Nerves. The Japanese Journal of Diabetic Caring, 10, 48-51. (In Japanese)

[32] Misawa, S., et al. (2013) Hyperglycemia Could Suppress Axonal Excitability and Pain in Diabetes. Peripheral Nerve, 24, 362-363. (In Japanese)

[33] Okuyama, T. and Terauchi, Y. (2013) Blood Glucose: Gender-Specific Medicine in Diabetes Mellitus. Journal of the Japan Diabetes Society, 56, 522-524. (In Japanese) 
Submit or recommend next manuscript to SCIRP and we will provide best service for you:

Accepting pre-submission inquiries through Email, Facebook, LinkedIn, Twitter, etc.

A wide selection of journals (inclusive of 9 subjects, more than 200 journals)

Providing 24-hour high-quality service

User-friendly online submission system

Fair and swift peer-review system

Efficient typesetting and proofreading procedure

Display of the result of downloads and visits, as well as the number of cited articles

Maximum dissemination of your research work

Submit your manuscript at: http://papersubmission.scirp.org/

Or contact health@scirp.org 